\title{
ANALISIS KEUNTUNGAN USAHA GULA MERAH DAN KONTRIBUSINYA TERHADAP RUMAH TANGGA DI KECAMATAN KARANG BARU KABUPATEN ACEH TAMIANG
}

\author{
Siti Balqies Indra ${ }^{1}$, Cut Gustiana ${ }^{2}$ dan Umi Kalsum ${ }^{2}$ \\ ${ }^{I}$ Dosen Fakultas Pertanian Universitas Samudra \\ ${ }^{2}$ Dosen Fakultas Pertanian Universitas Samudra \\ ${ }^{2}$ Mahasiswa Program Studi Agribisnis Fakultas Pertanian Universitas Samudra
}

\begin{abstract}
ABSTRAK
Penelitian ini dilakukan di Kecamatan Karang Baru Kabupaten Aceh Tamiang dengan menggunakan metode survey yaitu menyebar kuisioner dan melakukan wawancara. Objek penelitian ini adalah pengusaha gula merah di Kecamatan Karang Baru Kabupaten Aceh Tamiang. Ruang lingkup dalam penelitian ini adalah pengusaha gula merah di Kecamatan Karang Baru Kabupaten Aceh Tamiang yang tersebar di 4 Desa. Populasi dan sampel dalam penelitian ini adalah semua pengusaha gula merah yang ada di Kecamatan Karang Baru sebanyak 30 orang. Tujuan dari penelitian ini adalah untuk mengukur keuntungan gula merah dan seberapa besar kontribusinya terhadap pendapatan rumahtangga. Penelitian ini dilakukan pada bulan Mei sampai dengan bulan Juni 2018. Metode pengambilan sampel ini adalah dengan menggunakan Purposive Sampling.

Berdasarkan hasil penelitian diperoleh bahwa rata-rata biaya produksi usaha gula merah sebesar Rp.1.352.681, jumlah pendapatan bersih usaha gula merah di Kecamatan Karang Baru Kabupaten Aceh Tamiang adalah sebesar Rp.46.231.537 sementara jumlah pendapatan total rumah tangga pengusaha gula merah sebesar Rp.64.531.537. Untuk kontribusi gula merah diperoleh sebesar $72 \%$ yang artinya nilai kontibusi gulamerah > dari $50 \%$. Angka ini menunjukkan bahwa kontribusi usaha gula merah terhadap pendapatan rumah tangga di Kecamatan Karang Baru Kabupaten Aceh Tamiang tergolong tinggi.
\end{abstract}

Kata Kunci: pendapatan, usaha gula merah, kontribusi

\section{PENDAHULUAN}

Subsektor perkebunan memiliki
karakteristik tanaman yang dapat
dikelompokkan menjadi dua, yaitu tanaman
tahunan dan tanaman semusim. Tanaman
tahunan merupakan tanaman yang membutuhkan waktu lama untuk berproduksi dan dapat dipanen lebih dari satu kali. Contohnya seperti: kelapa sawit, karet, cengkeh, kakao, teh, aren, dan lain sebagainya. Aren atau enau (Arenga pinnata, Merr) merupakan salah satu komoditas tanaman perkebunan yangdapat tumbuh dengan baik di daerah tropis serta memiliki potensi nilai ekonomi tinggi karena hampir semua bagian tanamannya dapat memberikan keuntungan finansial, mulai dari akar yang bisa dijadikan obat-obatan. Dari batangnya dapat diperoleh ijuk, selain itu batang muda pohon aren dapat di ambil sagunya sedangkan batang tua pohon aren dapat dijadikan sebagai bahan furniture. Daun dapat dijadikan sebagai bahan untuk pembuatan atap. Bunga dijadikan sebagai bahan dasar pembuatan gula merah. Buah aren dapat dijadikan sebagai makanan seperti manisan kolang-kaling.

Gula merah diperoleh dengan menyadap tandan bunga jantan yang mulai mekar dan menghamburkan serbuk sari yang berwarna kuning. Tandan ini mula-mula dimemarkan dengan memukul-mukulnya selama beberapa hari, hingga keluar cairan dari dalamnya. Tandan kemudian dipotong dan diujungnya digantungkan tahang bambu untuk menampung cairan yang menetes. Cairan manis yang diperoleh dinamai nira, berwarna jernih agak keruh. Nira ini tidak tahan lama, maka wadah bambu yang telah berisi harus segera diambil untuk diolah niranya, biasanya sehari dua kali pengambilan yakni pagi dan sore (Muslimah, 2017:2).

Usaha gula merah di Kecamatan Karang Baru diproduksi dalam skala usaha rumah tangga dan umumnya berada di pedesaan. Proses produksi gula merah tersebut dikerjakan secara tradisional dengan menggunakan peralatan sederhana dan tenaga kerja yang digunakan adalah tenaga kerja yang berasal dari dalam keluarga. 
Permintaan gula merah sebagai bahan pengganti gula pasir dan pemanis buatan ini membuat aren menjadi komoditi andalan bagi para pengusaha gula merah. Nilai ekonomis yang dimiliki oleh produk-produk yang dihasilkan tanaman aren sangat dibutuhkan oleh pasar internasional sehingga berpeluang meningkatkan nilai ekspor yang berdampak pada peningkatan perekonomian nasional. Produk yang paling besar nilai ekonomisnya adalah gula merah (Burhanuddin, 2005)

Namun, proses produksi gula merah ditingkat petani daerah dilakukan dengan peralatan yang sangat sederhana, sehingga gula merah yang dihasilkan para pengrajin (petani) di daerah tidak dapat bertahan lama menyebabkan produktifitas gula merah di daerah tidak mampu mendorong ekspor gula merah, disamping itu kelemahan juga terletak pada harga jual gula merah yang sangat fluktuatif. Berdasarkan uraian diatas, maka peneliti tertarik untuk melakukan penelitian mengenai analisis tentang keuntungan usaha gula merah dan kontribusinya terhadap pendapatan rumah tangga di Kecamatan Karang Baru Kabupaten Aceh Tamiang

\section{Identifikasi Masalah}

1. Berapakah biaya produksi, penerimaan serta keuntungan usaha gula merah di Kecamatan Karang Baru Kabupaten Aceh Tamiang?

2. Seberapa besar kontribusi usaha gula merah terhadap pendapatan rumah tangga pengusaha gula merah di Kecamatan Karang Baru Kabupaten Aceh Tamiang?

\section{Tujuan Penelitian}

1. Untuk mengetahui biaya produksi, penerimaan dan keuntungan usaha gula merah di Kecamatan Karang Baru Kabupaten Aceh Tamiang.

2. Untuk mengetahui kontribusi usaha gula merah terhadap pendapatan rumah tangga pengusaha gula merah di Kecamatan Karang Baru Kabupaten Aceh Tamiang?

\section{Hipotesis}

Usaha gula merah memberikan kontribusi tinggi terhadap pendapatan rumah tangga di Kecamatan Karang Baru Kabupaten Aceh Tamiang

\section{METODE PENELITIAN}

\section{Lokasi, Objek, Ruang Lingkup Dan Waktu Penelitian}

Penelitian ini dilaksanakan di

Kecamatan Karang Baru Kabupaten Aceh Tamiang dengan menggunakan metode survei. Menurut Iskandar (2010:209), "metode survey adalah metode yang digunakan dalam penelitian yang dilakukan dalam pengamatan langsung terhadap suatu gejala dalam populasi besar atau kecil". Objek penelitian ini adalah pengusaha gula merah di Kecamatan Karang Baru Kabupaten Aceh Tamiang. Ruang lingkup penelitian hanya menganalisis keuntungan usaha gula merah dan kontribusinya terhadap pendapatan rumahtangga di Kecamatan Karang Baru Kabupaten Aceh Tamiang. Waktu penelitian dilaksanakan pada bulan Mei - Juni2018.

\section{Teknik Penentuan Sampel dan Pengumpulan Data PenentuanSampel}

Desa-desa yang menjadi sampel adalah Banai, Medang Ara, Paya Meta, dan Mananggini.

Tabel III-1. Jumlah Populasi dan Sampel Usaha Gula Merah di Kecamatan Karang Baru Kabupaten Aceh Tamiang

\begin{tabular}{|l|l|c|c|}
\hline No. & \multicolumn{1}{|c|}{ Desa } & Populasi(Orang) & Sampel(Orang) \\
\hline 1. & Banai & 10 & 10 \\
2. & MedangAra & 8 & 8 \\
3. & Paya Meta & 5 & 5 \\
4. & Mananggini & 7 & 7 \\
\hline \multicolumn{2}{|l|}{ Jumlah } & 30 & 30 \\
\hline
\end{tabular}

Sumber: Data Primer 2018

Variabel dan data yang dianalisis

a. Biaya produksi (Rp/Bln)

b. Produksi $(\mathrm{Kg} / \mathrm{B} \ln )$ c. Penerimaan atau pendapatan kotor $(\mathrm{Rp} / \mathrm{B} \ln )$

d. Keuntungan atau pendapatanbersih $(\mathrm{Rp} / \mathrm{B} \ln )$ 
e. Pendapatan diluar usaha gula merah (Rp/Bln)

f. Pendapatan total rumahtangga pengusaha gula merah (Rp/Bln)

g. Kontribusi usaha gula merah (\%)

Metode Analisis dan Pengujian Hipotesis

a. Analisis biaya produksi

$\mathrm{TC}=\mathrm{FC}+\mathrm{VC}$ (Rahim dan Diah, 2008:54)

Keterangan:

$\mathrm{TC}=$ Total Cost $($ Total biaya $)$

$\mathrm{FC}=$ Fixed Cost $($ Biaya tetap $)$

$\mathrm{VC}=$ Variable Cost (Biaya variabel $)$

b. Penerimaan

TR = P x Q (Soeharno, 2009:72)

Keterangan:

$\mathrm{TR}=$ Total Revenue $($ Penerimaan total $)$

$\mathrm{P}=$ Price (harga)

$\mathrm{Q}=$ Quantity (Jumlah produk yang dihasilkan)

c. Keuntungan

$\pi=$ TR - TC (Rahim dan Diah, 2008:60)

Keterangan: $\pi=$ Profit (Keuntungan)

$\mathrm{TR}=$ Total Revenue $($ Total penerimaan)

$\mathrm{TC}=$ Total Cost (Total biaya)

d. Kontribusi pendapatan usaha gula merah

$\mathrm{Kp}=\frac{x}{y} \mathrm{x} 100 \%$ (Rimbang, 2010:16)

Keterangan:

$\mathrm{Kp}=$ Kontribusi pendapatan usaha gula merah $(\%)$

$\mathrm{x} \quad=$ Pendapatan usaha gula merah (Rp/Bln)

$\mathrm{y} \quad=$ Pendapatan total rumahtangga usaha gula merah $(\mathrm{Rp} / \mathrm{Bln})$

Dengankriteriakeputusan:

a. Jika kontribusi usaha gula merah < $30 \%$ dari total pendapatan keluarga dikategorikan kontribusi rendah.

b. Jika kontribusi usaha gula merah 30 $-50 \%$ dari total pendapatan keluarga dikategorikan kontribusi sedang.

c. Jika kontribusi usaha gula merah > $50 \%$ dari total pendapatan keluarga dikategorikan kontribusi tinggi.

\section{HASIL DAN PEMBAHASAN}

Karakteristik Responden

Tabel V-1 Rata-rata Umur, Tingkat Pendidikan, Jumlah Tanggungan dan Pengalaman Usaha Gula Merah Responden, 2018

\begin{tabular}{|l|l|c|c|c|c|}
\hline \multirow{2}{*}{ No } & Nama Desa & $\begin{array}{c}\text { Umur } \\
\text { (Tahun) }\end{array}$ & $\begin{array}{c}\text { Tingkat } \\
\text { Pendidikan } \\
\text { (Tahun) }\end{array}$ & $\begin{array}{c}\text { Jumlah } \\
\text { Tanggungan } \\
\text { (Orang) }\end{array}$ & $\begin{array}{c}\text { Pengalaman } \\
\text { Usaha Gula } \\
\text { Merah (Tahun) }\end{array}$ \\
\hline 1 & Banai & 54 & 3 & 3 & 19 \\
2 & Medang Ara & 46 & 6 & 3 & 16 \\
3 & Paya Meta & 52 & 4 & 4 & 19 \\
4 & Mananggini & 50 & 7 & 4 & 13 \\
\hline \multicolumn{2}{|l}{ Jumlah } & 202 & 20 & 14 & 68 \\
\hline \multicolumn{2}{|l}{ Rata-rata } & 50 & 5 & 4 & 17.2 \\
\hline
\end{tabular}

Sumber : Data primer 2018 (diolah)

Pada tabel V-1 menunjukkan bahwa rata-rata umur responden pengusaha gula merah di Kecamatan Karang Baru Kabupaten Aceh Tamiang yaitu 50 tahun, dengan rata-rata tingkat pendidikan 5 tahun atau setara dengan

gula merah sebanyak 4 orang. Rata-rata pengalaman responden dalam menjalankan usaha produksi gula merah sudah mencapai 17 tahun.

kelas $5 \mathrm{SD}$, jumlah tanggungan pengusaha

\section{Produksi Gula Merah}

Tabel V-2 Rata-rata Produksi Gula Merah Per Bulan di Kecamatan Karang Baru Kabupaten Aceh Tamiang, 2018

\begin{tabular}{|c|l|c|}
\hline No & \multicolumn{1}{|c|}{ Nama Desa } & Produksi $(\mathrm{Kg} / \mathrm{Bln})$ \\
\hline 1 & Banai & 141 \\
2 & Medang Ara & 135 \\
3 & Paya Meta & 174 \\
4 & Mananggini & 141 \\
\hline
\end{tabular}




\begin{tabular}{|l|c|}
\hline Jumlah & 591 \\
\hline Rata-rata & 148 \\
\hline
\end{tabular}

Sumber : Data primer 2018 (diolah)

Berdasarkan tabel V-2 rata-rata produksi gula merah per bulan di Kecamatan Karang Baru Kabupaten Aceh Tamiang adalah sebanyak $148 \mathrm{Kg} /$ bulan. Desa dengan produksi gula merah terbanyak tiap bulannya adalah desa Paya Meta yaitu dengan produksi sebanyak $174 \mathrm{Kg} / \mathrm{bulan}$ dan terendah di Desa Banai dan Mananggini dengan produksi sebanyak 141 $\mathrm{Kg} / \mathrm{bulan}$. Keterbatasan pengusaha gula merah dalam memproduksi gula merah adalah terletak pada bahan baku nira yang masih sangat tergantung ketersediaannya berdasarkan cuaca dan kondisi alam, selain itu juga waktu produksi yang lama membuat pengusaha gula merah kesulitan untuk melakukan aktivitas lain terutama dalam melakukan kegiatan yang menambah pendapatan rumah tangga dan masalah utama yang menjadi kendala bagi pengusaha gula merah untuk meningkatkan produksinya adalah terkait bahan bakar selama proses produksi gula merah, bahan bakar yang digunakan adalah kayu bakar, saat ini, kayu bakar cukup sulit untuk didapatkan, harganya juga semakin semakin hari semakin tinggi. Banyak dari pengusaha gula merah yang membatasi produksi gula merah setiap harinya karena kendala-kendala tersebut.

\section{Biaya Produksi}

Tabel V-3 Rata-rata Total Biaya Produksi Gula Merah Per Bulan di Kecamatan Karang Baru, Kabupaten Aceh Tamiang, 2018

\begin{tabular}{|l|l|c|}
\hline No & Komponen Biaya & $\begin{array}{c}\text { Jumlah Biaya } \\
\text { (Rp/Bulan) }\end{array}$ \\
\hline A & Biaya Tetap (FC) & 1.500 \\
1. & Biaya Peralatan & 90.161 \\
2 & Biaya Sewa Tempat & 91.661 \\
\hline Total Biaya & \\
\hline B & Biaya Variabel (VC) & 356.370 \\
1. & Biaya Bahan Baku & 5.850 \\
& a. Air nira & 214.320 \\
2 & b. Kapur & 12.480 \\
& Biaya Bahan Penunjang & 672.000 \\
\hline & a. Kayu Bakar & 1.261 .020 \\
\hline b. Minyak Tanah & Biaya Tenaga Kerja & 1.352 .681 \\
\hline \multicolumn{2}{|l|}{ Tumlah } & \\
\hline
\end{tabular}

Sumber : Data primer 2018 (diolah)

Berdasarkan tabel V-3 rata-rata total biaya tetap usaha produksi gula merah sebesar Rp. 91.661,-/bulan, dimana biaya tetap terbesar terletak pada biaya sewa tempat yaitu sebesar Rp. 90.161,-/bulan, sementara biaya tetap terendah adalah biaya peralatan yaitu sebesar Rp. 1.500,-/bulan. Peralatan yang digunakan dalam usaha produksi gula merah meliputi; wajan, serokan, sendok makan, dan cetakan. Untuk rata-rata biaya variabel, biaya terbesar yang dikeluarkan adalah pada biaya upah tenaga kerja yakni sebesar Rp. 672.000,- per bulan. Semua tenaga kerja yang di pekerjakan dalam usaha gula merah ini merupakan tenaga kerja dalam keluarga, karena usaha gula merah ini merupakan usaha mikro dengan skala produksi rumah tangga, sebagian besar pengusaha gula merah menjadikan usaha gula merah sebagai usaha sampingan disamping memiliki usaha lain seperti usahatani dan usaha-usaha kecil lainnya. Biaya tertinggi kedua adalah biaya untuk membeli bahan baku, yakni sebesar Rp. 362.220,- per bulan, biaya bahan baku dihabiskan untuk pembelian air nira sebagai bahan baku utama dalam pembuatan gula merah dan bahan campuran untuk gula merah yaitu kapur. Biaya untuk bahan penunjang adalah biaya untuk membeli bahan bakar dalam pembuatan gula merah yaitu kayu bakar, yakni sebesar Rp.214.320,/bulan dan biaya untuk minyak tanah sebesar Rp.12.480,-/bulan. Total biaya untuk produksi gula merah per bulan di Kecamatan Karang 


\section{Biaya Tenaga Kerja}

Tabel V-4 Rata-rata Biaya Tenaga Kerja Usaha Gula Merah Per Bulan di Kecamatan Karang Baru Kabupaten Aceh Tamiang, 2018

\begin{tabular}{|c|l|c|}
\hline No & \multicolumn{1}{|c|}{ Nama Desa } & Biaya Tenaga Kerja (Rp/Bulan) \\
\hline 1 & Banai & 684.000 \\
2 & Medang Ara & 660.000 \\
3 & Paya Meta & 624.000 \\
4 & Mananggini & 720.000 \\
\hline Jumlah & 2.688 .000 \\
\hline \multicolumn{2}{|l|}{ Rata-rata } & 672.000 \\
\hline
\end{tabular}

Sumber : Data primer 2018 (diolah)

Berdasarkan tabel V-4 rata-rata biaya tenaga kerja tertinggi adalah di Desa Mananggini yaitu sebesar Rp.720.000,-/bulan dan terendah di Desa Paya Meta yaitu sebesar Rp. 624.000,-/bulan. Rata-rata keselurahan biaya tenaga kerja produksi gula merah di Kecamatan Karang Baru Kabupaten Aceh Tamiang adalah sebesar Rp. 672.000,-/bulan. Untuk kegiatan mengambil nira dan kegiatan memasak gula pengusaha gula merah mempekerjakan tenaga kerja dari dalam keluarga, hal ini dilakukan karena usaha yang dijalankan oleh pengusaha gula merah

\section{Pendapatan Usaha Gula Merah}

Tabel V-5 Rata-Rata Pendapatan Usaha Gula Merah di Kecamatan Karang Baru, Kabupaten Aceh Tamiang, 2018

\begin{tabular}{|c|l|c|}
\hline No & \multicolumn{1}{|c|}{ Nama Desa } & $\begin{array}{c}\text { Pendapatan } \\
\text { (Rp/Bulan) }\end{array}$ \\
\hline 1 & Banai & 1.451 .524 \\
2 & Medang Ara & 1.381 .356 \\
3 & Paya Meta & 2.215 .166 \\
4 & Mananggini & 1.369 .944 \\
\hline Jumlah & 6.417 .990 \\
\hline \multicolumn{2}{|l|}{ Rata-rata } & 1.604 .497 \\
\hline
\end{tabular}

Sumber : Data primer 2018 (diolah)

Berdasarkan tabel V-5 Rata-rata pendapatan usaha gula merah per bulan tertinggi adalah sebesar Rp.2.215.166,-/bulan yaitu di Desa Paya Meta dan terendah di Desa Mananggini yaitu sebesar Rp. 1.369.944,-/bulan, pendapatan tertinggi usaha gula merah di Kecamatan Karang Baru tergolong rendah hal ini dikarenakan pendapatan ini masih jauh dibawah UMR (Upah Minimun Regional) Provinsi Aceh tahun 2018 sebesar Rp. 2.700.000 per bulan. Berdasarkan hasil penelitian yang diperoleh hal ini disebabkan karena pengusaha gula merah memiliki kendala dalam meningkatkan produksi setiap harinya Faktor ini disebabkan karena proses berskala rumah tangga dengan tingkat produksi yang rendah. Rata-rata upah tenaga kerja untuk mengambil nira dan mengolah serta mencetak gula merah adalah 22.533,/bulan dimana kedua upah ini memiliki jumlah yang sama karena pekerjaan mengambil nira sedikit berat, tetapi waktunnya lebih singkat sedangkan mengolah dan mencetak gula merah waktu yang diperlukan lebih lama tetapi pekerjaan yang dikerjakan tidak begitu berat dibandingkan dengan mengambil nira. dalam memproduksi gula merah yang memakan waktu yang cukup panjang, jika memproduksi gula dalam jumlah yang cukup besar produsen harus mengeluarkan biaya yang besar untuk pembelian bahan bakar kayu. selain itu juga pengusaha gula merah tidak menjadikan usaha gula merah sebagai sektor utama dalam sumber pendapatan rumah tangga, pengusaha gula merah memperoleh sumber pendapatanlain dari kegiatan lain seperti usaha tani, bengkel, pegawai dsb. Kegiatan selain memproduksi gula merah ini yang menjadikan terbatasnya waktu pengusaha gula merah untuk memproduksi gula merah dalam jumlah besar. 
Pendapatan diluar Usaha Gula Merah

Tabel V-6 Rata-Rata Pendapatan diluar Usaha Gula Merah di Kecamatan Karang Baru, Kabupaten Aceh Tamiang, 2018

\begin{tabular}{|c|l|c|}
\hline No & \multicolumn{1}{|c|}{ Nama Desa } & $\begin{array}{c}\text { Pendapatan } \\
\text { (Rp/Bulan) }\end{array}$ \\
\hline 1 & Banai & 660.000 \\
2 & Medang Ara & 687.500 \\
3 & Paya Meta & 460.000 \\
4 & Mananggini & 557.143 \\
\hline Jumlah & 2.364 .643 \\
\hline Rata-rata & 591.161 \\
\hline
\end{tabular}

Sumber : Data primer 2018 (diolah)

Berdasarkan tabel V-6 rata-rata pendapatan diluar usaha gula merah di Kecamatan Karang Baru Kabupaten Aceh Tamiang adalah sebesar Rp.591.161,-/bulan. Pendapatan diluar usaha gula merah tertinggi terdapat di Desa Medang Ara yaitu sebesar Rp. 687.500,-/bulan dan terendah di Desa Paya Meta yaitu sebesar Rp. 460.000,-/bulan. Desa Paya Meta merupakan desa dengan pendapatan diluar usaha gula

merah terendah, hal ini disebabkan sebagian besar jenis pekerjaan responden disamping memproduksi gula merah adalah menjadi buruh tani dan supir becak. Secara keseluruhan sebagian besar pendapatan usaha diluar usaha gula merah diperoleh dari usaha tani, karena sebagian besar pekerjaan pengusaha gula merah disamping meproduksi gula merah adalah petani.

\section{Kontribusi Pendapatan Usaha Gula Merah Terhadap Pendapatan Rumah Tangga}

Tabel V-7 Kontribusi Pendapatan Usaha Gula Merah di Kecamatan Karang Baru, Kabupaten Aceh Tamiang, 2018

\begin{tabular}{|l|l|c|c|c|}
\hline No & Nama Desa & $\begin{array}{c}\text { Pendapatan Usaha Gula } \\
\text { Merah (Rp/Bulan) }\end{array}$ & $\begin{array}{c}\text { Pendapatan Total } \\
\text { Rumah Tangga } \\
\text { (Rp/Bulan) }\end{array}$ & Kontribusi (\%) \\
\hline 1 & Banai & 14.515 .244 & 21.115 .244 & 69 \\
2 & Medang Ara & 11.050 .851 & 16.550 .851 & 67 \\
3 & Paya Meta & 11.075 .832 & 13.375 .832 & 83 \\
4 & Mananggini & 9.589 .610 & 13.489 .610 & 71 \\
\hline \multicolumn{2}{|l|}{ Jumlah } & 46.231 .537 & 64.531 .537 & 72 \\
\hline
\end{tabular}

Sumber : Data primer 2018 (diolah)

Berdasarkan tabel V-7 dapat dilihat bahwa kontribusi pendapatan gula merah tertinggi adalah Desa Paya Meta dengan kontribusi sebesar $83 \%$ dan terendah adalah Desa Medang Ara yaitu sebesar $67 \%$. Secara keseluruhan rata-rata kontribusi pendapatan gula merah di Kecamatan Karang Baru Kabupaten Aceh Tamiang adalah sebesar $72 \%$ yang artinya kontribusi pendapatan usaha gula merah $>50 \%$ dari total pendapatan keluarga.

\section{KESIMPULAN DAN SARAN}

\section{Kesimpulan}

1. Biaya produksi per bulan gula merah di Kecamatan Karang Baru Kabupaten Aceh Tamiang adalah sebesar Rp. 1.352.681,-
2. Pendapatan bersih per bulan usaha gula merah di Kecamatan Karang Baru Kabupaten Aceh Tamiang adalah sebesar Rp. 1.541.051

3. Kontribusi usaha gula merah terhadap pendapatan rumah tangga pengusaha gula merah di Kecamatan Karang Baru Kabupaten Aceh Tamiang sebesar $72 \%$

4. Kontribusi pendapatan usaha gula merah di Kecamatan Karang Baru tergolong tinggi karena kontribusi $>50$ $\%$

\section{Saran}

1. Diharapkan pemerintah mampu mendorong pengusaha gula merah untuk meningkatkan produksi gula merah dengan memberikan motivasi bsinis 
dikalangan pengusaha melalui pembentukan kelompok pengusaha mikro.

2. Diharapkan pemerintah mampu memberikan sumber modal bagi pengusaha gula merah berupa alat dan mesin dengan teknologi terbaru untuk pembuatan gula merah sehingga pengusaha dapat memaksimalkan waktu kegiatan produksi dan meningkatkan produksi secara maksimal.

\section{DAFTAR PUSTAKA}

Anonimous. 2016. Badan Pusat Statistik Aceh Tamiang.

Bank Indonesia.2008. Pola Pembiayaan Usaha Kecil (PPUK) Gula Semut dan Gula Merah. Bank Indonesia, Jakarta

Burhanuddin. 2005. Prospek Pengembangan Usaha Koperasi Dalam Produksi Gula Aren, Jakarta.

Effendi, Muchtar., dkk. 2013. Studi Potensi Tanaman Aren (Arenga Pinnata) di Desa Batang Kulur, Kandangan Kabupaten Hulu Sungai Selatan. Laporan Penelitian Fakultas kehutanan Universitas Lambung Mangkarut, Banjar Baru.

Pratama, Fery. 2015. Pembuatan Gula Kelapa Aren Terfermentasi Alami (Kajian Pengaruh Konsentrasi Anti Inversi dan Natrium Metabisulfit). Malang. Jurnal Pangan dan Agroindustri Vol.3 No.4, Malang.

Ghafar PA, Heryani S. 2012. Pengembangan Proses Pengolahan Minuman Nira Aren Dengan Teknik Ultrafiltrasi Dan Deodorasi. Jurnal Hasil Penelitian Industri.

Guritno. 2000. Kamus Ekonomi. Universitas Gajah Mada press, Yogyakarta.

H, Abbudin Nata, 2012. Kapita Selekta Pendidikan Islam. Jakarta: PT. Raja Grafindo Prasada

Imam, F. 2013. Analisis Kelayakan Finansial Usaha Penggilingan Kopi di Kecamatan Idi Rayeuk Kabupaten Aceh Timur. Skripsi Jurusan Agribisnis Fakultas Pertanian Universitas Samudra, Aceh.

Iskandar. 2010. Metode Penelitian Pendidikan Dan Social (Kuantitatif Dan Kualitatif). Gaung Persada Press (GP Press), Jakarta.

Lempang, Mody. 2012. Pohon Aren Dan Manfaat Produksinya. Jurnal Info
Teknis EBONI. Vol. 9 No. 1: 37-54. Balai Penelitian Kehutanan, Makassar.

Marthen, Theogives Lasut,. 2012. Budidaya yang Baik Aren (Arenga pinnata (Wurmb) Merr). Penebar Swadaya, Bogor

Mulyadi, 2012. Akuntansi Biaya. Edisi ke-5. STIM YKKPN, Yogyakarta.

Muslimah dan Alimsyahputra. 2017. Analisis Kelayakan Finansial Usaha Pengolahan Gula Aren di Kecamatan Rantau Kabupaten Aceh Tamiang. Jurnal Penelitian. Vol. 4 No. 2.Program Studi Agribisnis Fakultas Pertanian Universitas Samudra, Langsa.

Nainggolan, Romauli 2016, Gender, Tingkat Pendidikan, dan Lama Usaha Sebagai Determinan Penghasilan UMKM Kota Surabaya, Jurnal: Kinerja Volume 20, No 1)

Prawirokusumo. 2005. Kewirausahaan dan Manajemen Usaha Kecil. BPFE, Yogyakarta

R, Rosidah dan Arfa Agustina. 2015. Pengolahan Gula Aren Di Desa Banua Hanyar Kabupaten Hulu Sungai Tengah. Jurnal Hutan Tropis Volume 3 No.3, Kalimantan Selatan.

Rahim, A dan Diah, R.D.H. 2008. Pengantar Teori dan Kasus Ekonomika Pertanian. Penebar Swadaya, Jakarta.

Rimbang. 2010. Kontribusi Usaha Ternak Kambing Terhadap Pendapatan Rumah Tangga di Desa Kendal Bulur Kecamatan Boyolangu, Kabupaten Tulungagung. Abstrak Fakultas Peternakan UGM, Yogyakarta., Andi, Yogyakarta.

Sukirno, Sadono. 2014. Mikroekonomi Teori Pengantar. Raja Grafindo Persada, Jakarta.

Soeharno. 2009. Teori Ekonomi Mikro. PT. Raja Grafindo Persada, Jakarta.

Sugiyono. 2010. Metode Penelitian Pendidikan Pendekatan Kuantitatif, Kualitatif dan $R \& D$. Alfabeta, Bandung.

Sulistyo, Indah Utami. 2002. Petunjuk Praktis Pengolahan Gula Kelapa.Petunjuk Praktis Pengolahan Gula Kelapa, Minyak Kelapa, dan Pati Ganyong. Tim Fakultas Teknologi Pertanian UniversitasGadjah Mada. Yogyakarta.

Yandianto. 2000. Kamus Umum Bahasa Indonesia. M2S Bandung, Bandung. 